\title{
Um cometa chamado JOTA: Pesquisas recentes em Estudos da Tradução, Estudos da Adaptação e Intersemiótica
}

Para vos, querida Graciela Escande

Silvia Cobelo*1

Esta edição da Revista Tradterm é um número especial dedicado à III Jota 2019, proporcionando aos leitores a oportunidade de apreciar a diversidade e interdisciplinaridade de pesquisas em Estudos da Tradução e Adaptação no país. A cada dois anos o Grupo de Estudos de Adaptação e Tradução - GREAT (FFLCH-USP/CNPq) organiza a JOTA - Jornada de Tradução e Adaptação, um dos poucos eventos com foco nesses estudos no Brasil, com inequívoca ênfase nos Estudos da Adaptação.

A jornada de 2019, celebrada na USP, foi aberta por Deborah Cartmell², com a conferência "Adaptation, Marketing and the Decline and Rise of Shakespeare in Classical Hollywood"3, um estudo historiográfico de adaptações shakespearianas para o cinema, desde os primeiros filmes feitos na chamada era clássica hollywoodiana, entre 1920 e 1930. Cartmell mostra o

\footnotetext{
"Universidade de São Paulo.

1 Este texto não só foi revisado por minha dedicada colega nesta Comissão Editorial, a pesquisadora e tradutora Solange Pinheiro, como também reconheço suas valiosas contribuições durante a escritura, as quais certamente deram o brilho final à apresentação.

${ }^{2}$ Com grande produção bibliográfica dentro dos Estudos da Adaptação e Cinema, a professora da Montfort University, UK, é uma das fundadoras da Association of Adaptation Studies, além de coeditora das revistas Adaptation (Oxford University) e Shakespeare (Routledge).

${ }^{3}$ A conferência de Cartmell e outras palestras foram gravadas pelo canal da FFLCH-USP e estão disponíveis na playlist III Jota 2019, no canal do GREAT. Disponível em: https: / / www.youtube.com/watch?v=DAdtPHHkm7U\&list=PLJRmCOArTXHNVfAfFIFZj99QeUFbi 9JyL\&index $=5$. Acesso 29 jan. 2021.
}

TradTerm, São Paulo, v.38, fevereiro/2021, p. 1-19

Número Especial - III JOTA

www.revistas.usp.br/tradterm 
lado menos glamoroso da indústria, a comercialização, algo pouco explorado pelas pesquisas, as quais prestam mais atenção à parte artística das obras. Ressalta a importância das adaptações no mercado internacional de cinema, responsáveis por garantir produtos que englobem a diversidade de diferentes países/culturas com filmes relevantes e adequados às suas necessidades e expectativas.

Os trabalhos de Estudos da Tradução e Adaptação, separados aqui em duas partes, cada uma com oito artigos, são precedidos por "Que Mil Flores Desabrochem!”. O curto prefácio escrito por John Milton, líder do GREAT e presidente da JOTA, discorre sobre o amplo leque de adaptações surgido com o advento da internet e mídias sociais; e confirma a dificuldade de definir o que não é uma adaptação, assim como de estabelecer limites rígidos entre tradução e adaptação.

A primeira parte, dedicada aos Estudos da Tradução, expõe a diversidade de pesquisas realizadas na área e é iniciada por Maria Silvia Cintra Martins com um artigo multidisciplinar. A autora oferece um inédito diálogo teórico entre a proposta de Henri Meschonnic sobre a Antropologia da Linguagem com a obra da premiada escritora sul-coreana Han Kang, Leçons de Grec (2019) [Greek Lessons, 2011]. Reflete sobre os desafios dessa tradução ao português, produzida por sua aluna e um trecho de uma das cartas de Van Gogh (1914) em versão inglesa, e sua primeira tradução ao português, objeto de pesquisa outra de suas orientandas. Martins analisa as diferentes produções escritas através de sua metodologia do 'jogo de espelhos' que confronta e constrói um diálogo entre distintos autores, trabalhando elementos como panrítimica, o silêncio e a escuta. Como ela mesma magistralmente conclui, a tarefa do tradutor se apresenta como um exemplo da vocação para o "provisório, para o tentativo, para o inacabado, para aquilo que está por vir, para o ainda desconhecido".

Meschonnic está presente também nos três artigos dos orientandos de Martins. Julio César Ribeiro dos Santos nos conduz ao campo musical através de seu artigo "Tatit, Meschonnic e a tradução de Caipira (Marques; Macaraí 1992): diálogos e desafios iniciais", no qual estabelece uma relação entre a Semiótica da Canção e Estudos da Tradução. Santos discorre sobre a canção TradTerm, São Paulo, v.38, fevereiro/2021, p. 1-19 
Caipira de Joel Marques, gravada em 1992 pela dupla Chitãozinho \& Xororó, regravada 15 anos depois pelos mesmos irmãos com uma tradução intralingual da letra, na qual inserem elementos da oralidade da língua portuguesa. Justamente pelo desprestígio do gênero nos anos 1970, inicialmente a dupla não quis ser reconhecida como caipira, mas com o sucesso da música sertaneja, e dos próprios irmãos, eles assumiram orgulhosamente sua variante linguística de origem, e gravaram essa "tradução para o caipirês", como marca Santos, pois assim como os cancionistas, Joel Marques e Macaraí, Chitãozinho \& Xororó não nasceram em ambientes urbanos. Julio César Ribeiro dos Santos emprega também em sua cuidadosa análise, conceitos como ritmo e panrítmica.

João Paulo Ribeiro nos apresenta a cosmologia xamânica através da eloquência sonora da poesia ameríndia. "Com o mbaraká nas mãos das palavras: traduzindo poesia indígena guarani”, é um elucidativo artigo com base antropológica, ofertando trechos traduzidos do canto jeroky de um dos clássicos ameríndios, Ayvu Rapyta - Textos Míticos de los Mbyá-Guarani del Guairá (1959), publicada pela primeira vez pelo etnólogo paraguaio Leon Cadogan. Ribeiro analisa diferentes traduções do poema, detendo-se em como alguns termos são apresentados em cada versão, finalizando com sua própria tradução, para a qual utiliza um instrumento musical indígena sagrado, o mbaraká. Ribeiro desvela suas reflexões sobre o trajeto tradutório, esclarecendo algumas opções, inclusive ao decidir não traduzir, deixando a palavra em guarani, como foi o caso de Yvára; mostrando também as escolhas de seus colegas anteriores, que a traduziram como divino/divina, céu e deus.

Também utilizando a metodologia do 'jogo de espelhos' de Martins, Andrêi Krasnoschecoff delineia uma inovadora relação entre Semiótica e os Estudos da Tradução ao examinar versos do poema $O$ Corvo (1845) de Edgar Alan Poe e duas traduções ao português, uma brasileira, assinada por Machado de Assis (1883) e a outra portuguesa, por Fernando Pessoa (1924). Krasnoschecoff busca o ponto de contato entre Meschonnic e sua crítica sobre o ato de traduzir e o funcionamento da linguagem e a tripartição do signo como compreendido por Pierce. Dialogando também com Haroldo de Campos

TradTerm, São Paulo, v.38, fevereiro/2021, p. 1-19

Número Especial - III JOTA

www.revistas.usp.br/tradterm 
e Yuri Lotman, ele apresenta algumas observações pertinentes sobre o papel desempenhado pela memória na interpretação e tradução de obras literárias.

A tradução teatral é abordada em três artigos: três culturas distintas, escritas em tempos diversos, e com abordagens e referências variadas.

Rodrigo lelpo reflete sobre a importância das rubricas na tradução da peça Les Cenci (1935). Escrito e produzido por Antonin Artaud, o drama adapta outro, escrito por Percy Shelley, The Cenci (1819), além de utilizar elementos do conto de Stendhal (1837), com mesmo título. A encenação de Artaud, em ressonância com sua teoria para um Teatro da Crueldade ${ }^{4}$, é mal recebida e termina após 17 apresentações. Segundo lelpo, “Artaud expõe a máquina semiótica que deveria comandar a montagem, engendrando, por meio da rubrica, a passagem do texto ao espetáculo". Ao notar que a relação entre as rubricas e os diálogos possibilita a tradução da força expressiva do drama francês, lelpo compartilha generosamente os princípios que poderão nortear uma tradução comentada da peça, respeitando a relevância das didascálias na obra de Artaud,

O artigo "Tradução coletiva e criativa do Entremés de la Ropavejera, de Quevedo y Villegas”, assinado por Andrea Cesco e Beatrice Távora, faz uma viagem ao Século de Ouro, longo período ${ }^{5}$ do auge da cultura espanhola, no qual surgem nomes como Miguel de Cervantes, Lope de Vega, Góngora, Pedro Espinosa, Calderón e claro, o fidalgo Francisco Gómez de Quevedo y Santibáñez Villegas. Resultado de uma tradução em equipe, as autoras apresentam o curioso entremez escrito em 1670 sobre uma remendeira e seus clientes ansiosos em reparar os estragos da passagem dos anos e recuperar a juventude. Assim como o autor anterior, Cesco e Távora nos mostram, dadivosas, os passos do processo tradutório e seu resultado, publicado em

\footnotetext{
${ }^{4}$ Teatro da Crueldade é um projeto de teatro experimental proposto pelo próprio Artaud, uma grande influência para o teatro de vanguarda do século XX. Artaud acreditava que a civilização transformara humanos em criaturas doentes e reprimidas, e a verdadeira função do teatro seria a de livrar a humanidade dessas repressões e liberar a energia instintiva de cada indivíduo. Ele propõe a remoção da barreira do palco, aproximar artistas e público, espetáculos míticos com gemidos, gritos, efeitos de luz, e grandes adereços de palco. Encyclopedia Britannica: Disponível em: https://www.britannica.com/topic/Theatreof-Cruelty. Acesso 29 jan. 2021.

${ }^{5}$ Considera-se que dura mais de um século, desde a chegada de Colombo na América em 1492 até a morte de Calderón de la Barca em 1681.
}

TradTerm, São Paulo, v.38, fevereiro/2021, p. 1-19

Número Especial - III JOTA

www.revistas.usp.br/tradterm 
uma inédita e necessária coletânea de traduções brasileiras de dramaturgia desse período áureo.

Amanda Bruno de Mello nos conduz ao século XX, mais especificamente aos turbulentos anos 1970 na Itália, com seu artigo “Os desafios de traduzir o humor político para o português: escolhas tradutórias para Tutta Casa, Letto e Chiesa, de Franca Rame e Dario Fo". Mello inicia seu artigo com uma informação bem significativa. Dario Fo dizia ser o Nobel recebido em 1997 ser prêmio para sua obra conjunta com Franca Rame, companheira de vida e pluma, não agraciada oficialmente. A peça do casal italiano sobre a igualdade entre os gêneros apresenta o conturbado contexto histórico da época ${ }^{6}$ com um tom cômico, desafiando a tradução a conciliar elementos antagônicos, como a falta de familiaridade com os temas políticos provocadores do riso. 0 texto é bem conhecido no Brasil através da montagem assinada pelo premiado diretor de teatro e televisão, o paulista Roberto Vignati, Brincando em Cima Daquilo $(1984)^{7,8}$, sem as alusões ao problemático contexto político, mas excelente resultado de público. Segundo a própria Mello (2019), a peça de Rame e Fo foi encenada também com a atriz Denise Stoklos, sob direção de Antônio Abujamra e tradução de Zilda Daeier. Provocante, Um Orgasmo Adulto Escapa

\footnotetext{
${ }^{6}$ No Capítulo "Lo stupro by Franca Rame: Political Violence and Political Theatre", Luciana d' Arcangeli (2009:102-104) estuda esse conflituoso e brutal período, detalhando o sequestro, estupro e espancamento da artista. Membro do PCI desde 1967, foi raptada em 1973 por um grupo neofascista, a mando de oficiais de alto rango no departamento de polícia. Rame foi violada, e torturada com giletes, queimada com cigarros e surrada antes de ser deixada num parque.

${ }^{7}$ A comédia recebeu cinco prêmios, inclusive um Molière para Marília Pêra, protagonista do monólogo. O próprio Vignati reencenou seu texto em 2018, com Nina Rocha no papel principal. Com evidente gosto pela adaptação, Vignati assina outros textos do casal, por exemplo, Um Casal Aberto, Ma Non Troppo (1984) todos um sucesso de bilheteria; assim como outras obras: as peças A Hora da Estrela (1998) e Vidas Secas (2003), entre várias. Em 2017 o ator paulista Wilson de Santos proferiu os monólogos traduzidos por Vignati vestindo figurino feminino, e mantendo o título de duplo sentido, após autorização de Jacopo Fo, filho dos autores italianos.

Disponível em: http://enciclopedia.itaucultural.org.br/pessoa397784/roberto-vignati e https: //www.salvadornoticias.com/2017/12/teatro-brincando-em-cima-daquilo.html. Acesso 29 jan. 2021.

${ }^{8} \mathrm{O}$ texto de Fo e Rame foi traduzido por Roberto Vignati e Michele Piccoli. Mostrando a falta de reconhecimento dos tradutores na década de 1980, não encontramos na Internet informações sobre Piccoli. Todas as pesquisas feitas com esse nome remetem ao ator Michel Piccoli; portanto, sugerimos aos próximos pesquisadores uma consulta ao próprio Roberto Vignati, pois tampouco encontramos referencia alguma sobre essa peça na biografia do ator francês.
}

TradTerm, São Paulo, v.38, fevereiro/2021, p. 1-19

Número Especial - III JOTA

www.revistas.usp.br/tradterm 
do Zoológico (1983) foi apresentada no Brasil e no exterior durante três anos, abismando o público com suas representações mímicas e clownescas.

Mello exemplifica o desafio de sua empreitada para manter o estranhamento recriando elementos domésticos com três exemplos. 0 título e seu jogo de palavras é o primeiro; seguido de uma criativa e intertextual solução em um trecho com uma poesia com nomes de órgãos sexuais masculinos sendo comparada com palavras ligadas ao corpo da mulher. 0 terceiro é a inserção de um prólogo, voltando ao texto de origem, reproduzindo "uma característica recorrente no teatro épico de Rame e Fo", esclarecendo melhor o monólogo traduzido?.

Nesta seção, temos ainda o prazer de oferecer o trabalho representando a nova geração de pesquisadores nesta área, o artigo da participante premiada pelo seu pôster em nossa jornada, Natalia Ferrigolli, assinado em conjunto com sua orientadora, Lenita Maria Rimoli Pisetta. Ferrigoli nos presenteia com trechos traduzidos ao português em prosa do poema Midsummer Night and Other Tales in Verse (1928), de John Masefield. 'Poeta Laureado' oficial do Reino Unido desde 1930 até sua morte em 1967 e praticamente desconhecido entre nós, Masefield proporciona mais uma das inúmeras variantes da lenda arturiana, e a tradução de Ferrigolli permite que leitores brasileiros entrem em contato com essa nova visão do mundo de Arthur e Guinevere e os Cavaleiros da Távola Redonda, tema presente no imaginário coletivo ocidental há muitos séculos. Assim como acontece com as adaptações dentro da Literatura Infantojuvenil (LIJ) e quadrinhos/graphic novel, e audiovisuais, como filmes, seriados e musicais, ao transformar em prosa os versos do poeta, a tradução aproxima a narrativa cavalheiresca do público contemporâneo, ao narrar o texto poético, mais hermético.

Justamente por utilizar técnicas adaptativas, e com resultado digno de ser publicado como adaptação autoral para público LIJ, o artigo fecha o segmento sobre Tradução, com um prelúdio para o próximo.

$\mathrm{Na}$ segunda parte do número especial encontramos pesquisas na área dos Estudos da Adaptação. Exceto o primeiro, dentro dos estudos de

\footnotetext{
${ }^{9}$ Essa obra teve outro monólogo recentemente estudado em outra dissertação de mestrado, com uma tradução anotada por Cristiana Almeida de Sousa (2019).
}

TradTerm, São Paulo, v.38, fevereiro/2021, p. 1-19

Número Especial - III JOTA

www.revistas.usp.br/tradterm 
Intermedialidade, que examina a adaptação de um livro em uma exposição; os outros artigos observam adaptações cinematográficas e teatral de obras literárias.

Vale fazer um pequeno parêntesis teórico aqui, pois os Estudos da Adaptação ainda não são tão populares como os Estudos da Tradução, especialmente dentro das pesquisas feitas no Brasil, recebendo mais atenção acadêmica a partir deste milênio, apesar de coexistir com a tradução desde os primórdios de nossa cultura.

Poucos hesitam ao identificar uma tradução integral de uma obra, a qual pode passar por uma ação tradutória mais literal ou mais livre, sempre com a proposta de verter um texto fonte para outra língua/cultura, sem omitir ou adicionar elementos estranhos ao ato de traduzir em si. Já no caso de uma adaptação, temos uma miríade de formas, processos e produções distintas, demandando ajuda de um manual, como, por exemplo, o Handbook of Translation Studies (2013). No primeiro verbete, “Adaptation”, John Milton (2013: 3) recorda ser um termo amplamente usado para adaptações de obras na área de literatura, teatro, dança, música, videogames, produções de vídeo, televisivas e fílmicas. Reconhece, no entanto, ser uma área de estudos com terminologia cheia de nuances e vocábulos auto explanatórios, como apropriação, recontextualização, redução, simplificação, condensação, resumo, versão especial, transformação, remediação, tradaptação, além das palavras importadas, ainda sem tradução para nossa língua: spin-off, sequel, prequel, remix, mashup, entre outras formas de reescrituras.

Milton retoma a definição de Julie Sanders (2006: 18-19), que descreve como operativa: um texto modificado (por omissões, adições, reescrituras etc.), mas ainda reconhecível como derivado de outro, criado anteriormente. Ele relaciona essa definição com aquela de 'paráfrase' feita por John Dryden (1956: 182, apud Milton 2013: 3), na qual o tradutor conserva a ideia do autor da obra fonte e o ponto de enunciação, mas sem se apegar de maneira rigorosa à fonte.

Milton comenta o contraste entre Adaptação e Apropriação feita por Sanders, notando semelhanças com o conceito de 'imitação' de Dryden, no

TradTerm, São Paulo, v.38, fevereiro/2021, p. 1-19

Número Especial - III JOTA

www.revistas.usp.br/tradterm 
qual o tradutor/adaptador assume a liberdade não só de alterar palavras e sentidos, mas também de esquecê-los assim que tiver a ocasião, escolhendo apenas alguns detalhes da obra matriz, seccionando-a ao seu gosto.

John Milton recomenda alguns estudos abordando traduções/adaptações intersemióticas de obras literárias para cinema e dramaturgia, como Phillys Zatlin (2005), Gillian Lathey (2006), Milton e Torres (2003). Adicionamos Robert Stam, autor muito utilizado em análises de adaptações fílmicas, cujo livro Introdução à Teoria do Cinema (2000) traduzido por Fernando Mascarello, está na quinta edição/reimpressão (2020) ${ }^{10}$, Tomas Leitch (2017), Sarah Cardwell (2002), Kamilla Elliot (2003) e, claro, a convidada de honra da III Jota 2019, Deborah Cartmell (2012, 2017).

Infelizmente, além Stam e algum outro crítico, poucos são traduzidos para o português, e mesmo para o espanhol, dificultando a atualização dos estudiosos brasileiros. Uma das exceções é Linda Hutcheon, uma das autoras mais citadas dentro dos estudos feitos no país. Sua obra, A Teoria da Adaptação, traduzida no Brasil por André Cechinel em 2011, foi republicada em 2013, e está com edição esgotada. Mas o texto já foi atualizado em 2013. Hutcheon convidou Siohban O'Flynn, que acrescentou um essencial epílogo sobre adaptação dentro do mundo digital e mídias sociais, projetando a diversidade mediática vivida hoje.

Todo espetáculo audiovisual é precedido de um texto guia, um roteiro, um libreto, ou enredo no caso de escolas de samba, com rubricas descrevendo cenários, vestuários, características físicas e emocionais das personagens, estabelecendo a entrada de suas falas em forma de diálogos - elementos e detalhes todos textos escritos geralmente por outro indivíduo, um adaptador, que não o diretor do espetáculo, filme, ópera ou musical, peça ou desfile de carnaval.

Mesmo assim, não é incomum, encontrar certa confusão autoral: Diretores são tidos como únicos responsáveis por todos os detalhes da produção, sem levar em conta a existência de um grupo imenso de pessoas

\footnotetext{
${ }^{10}$ Não tivemos acesso a todas as edições para poder afirmar se a denominação 'quinta edição' procede. Se não existir modificação de texto/imagens/paratextos, é uma reimpressão.

TradTerm, São Paulo, v.38, fevereiro/2021, p. 1-19

Número Especial - III JOTA

www.revistas.usp.br/tradterm
} 
trabalhando no complexo processo de adaptar uma obra literária para as telas.

Sem desmerecer nem retirar a importância criativa do diretor, muitas vezes ele mesmo o criador da história/ideia original [story by], ou escritor ou colaborador no roteiro ${ }^{11}$, ressaltamos a necessidade de valorizar o papel e reconhecer a autoria do adaptador, nem sempre a mesma pessoa que dirige. O diretor orquestra toda a produção, impinge sua marca, o seu conceito de como aquele roteiro será transformado em um filme, no caso do cinema, mas não deve receber toda a atenção e até crédito como adaptador. Como recordam Fernanda Martins Ferreira de Araújo e Liliam Cristina Marins em seu artigo, uma obra como um filme/série é resultado de um ato coletivo, um esforço de uma equipe coesa e afinada, na qual cada um tem sua função e todos são importantes. Infelizmente, esses profissionais costumam recebem atenção somente por ocasião de grandes premiações da indústria.

Toda filmagem/gravação é produzida conforme indicações bastante precisas de um blueprint, um roteiro, recebido e lido por todos da equipe. A produção de um audiovisual exige que, além de obviamente o diretor e atores, todos os integrantes do projeto saibam exatamente 'onde/quando/como estar', desde produtores, gerente de locação, diretor de arte, figurino, maquiagem, departamento de fotografia e seus assistentes, departamento de elétrica, maquinaria, assistentes de direção, e o pessoal da pós-produção.

A vantagem para nós, estudiosos, é a possibilidade de analisar e comparar os roteiros com a obra fonte, como também com o produto final, 0 filme (ou audiovisual em questão) pronto, aquele visto pelo público, no qual é mais evidente a assinatura autoral de seu diretor, que pode ter ou não interferido na edição final, pois certamente a manipulação feita pelo editor, interfere na versão final do filme comercializado.

\footnotetext{
${ }^{11}$ Muitas vezes um roteirista é chamado como script doctor, trabalhando sobre o texto de um autor, editando, cortando e adicionando cenas, dando ritmo ao filme, muitas vezes solucionando problemas de enredo ou até mesmo de produção, outras reescrevendo cenas inteiras ou até modificando gêneros, idades, contextos de personagens e modificando o final. É bastante comum a omissão desses colaboradores nos créditos finais, especialmente em produções mais antigas.
}

TradTerm, São Paulo, v.38, fevereiro/2021, p. 1-19

Número Especial - III JOTA

www.revistas.usp.br/tradterm 
O primeiro artigo desta parte, uma coautoria de Rodrigo Corrêa Gontijo e Paulo Edson Alves Filho, convida o leitor a mergulhar na produção e montagem da exposição A Beleza Sombria dos Monstros: 10 anos da Arte de Tim Burton (2019) ${ }^{12}$, feita para celebrar dez anos da publicação do livro The Art of Tim Burton (2009), escrito pelo próprio artista, nativo de Burbank, uma região com muitos estúdios, o coração daquilo conhecido por 'Hollywood', dado importante em sua biografia artística.

Completamente original e com participação presencial de Burton, a exposição adapta personagens e cenários idealizados pelo diretor, através das recentes tecnologias de linguagem digital, proporcionando aos visitantes uma experiência interativa pelos ambientes imersivos e sensoriais que reúnem quatro décadas de materiais de pesquisa e referências utilizadas em seus filmes. Os autores ponderam sobre a transposição das personagens do primeiro capítulo ${ }^{13}$ na sala Monstros Incompreendidos, uma das estações multimídia que recriaram e expandiram o livro: "As ilustrações, transformadas em filmes de suspense e fantasia, retrocederam mais de um século e foram convertidas em brinquedos óticos inspirados no pré-cinema". Edward é representado através de um autômato e teatro de sombras. Já Batman, Catwoman e Penguin foram adaptados para a exposição com ajuda de uma lanterna mágica automatizada, homenageando o conhecido sinal luminoso projetada nos céus de Gotham City.

Segundo Gontijo e Alves Filho, Burton tem especial apreço por técnicas artesanais e/ou históricas, evidente em Nightmare Before Christmas (1993) [0 Estranho Mundo de Jack] e Frankenweenie (2012), portanto os adaptadores desenvolveram um tríptico com flipbooks mecanizados, mostrando o

\footnotetext{
12 A mostra foi organizada para o Centro Cultural Banco do Brasil (Brasília) em 2019, pela RUA 34 PRODUÇõES, com colaboração de TIM BURTON PRODUCTIONS e da curadora americana Jenny He e designer Holly Kempf, e direção de Leo Rea Lé. Foram convidados artistas brasileiros envolvidos com linguagens digitais e experiências imersivas, para criar as 14 galerias (correspondendo aos 14 capítulos). Correio Brasilense [28 maio 2019]. Disponível em: https://www.correiobraziliense.com.br/app/noticia/diversao-earte/2019/05/28/interna_diversao_arte,757952/mundo-de-tim-burton-chega-a-capital-commostra-no-ccbb.shtml. Acesso 29 jan. 2021.

${ }^{13}$ Além do próprio Gontijo, os outros responsáveis por essa adaptação do primeiro capítulo, segundo citação no artigo são: Maurício Jabur (desenvolvimento tecnológico), Márcia Porto (ilustrações), Agnaldo Pinho (bonecos), Pedro Febrônio (artefatos e arte) e Paulo Emílio (assistência geral).
}

TradTerm, São Paulo, v.38, fevereiro/2021, p. 1-19

Número Especial - III JOTA

www.revistas.usp.br/tradterm 
movimento (ilusório) das personagens, deslocam-se de um flipbook para o outro. No último caso descrito, adaptando o musical Sweeney Todd: The Demon Barber of Fleet Street (2007), o protagonista é transposto a um praxinoscópio estilizado e mecânico, com imagens do mesmo Burton. A exposição assombrou pelas proporções reais e vívidas, numa criativa demonstração de adaptação intersemiótica utilizando multimídia.

$\mathrm{O}$ artigo “A adaptação da narrativa-game de Halliday's Easter Egg Hunt para o filme Ready Player One" de Fernanda Martins Ferreira de Araújo e Liliam Cristina Marins inaugura nossa seção de adaptações de livros em filmes, com um sabor de videogames, estuda o jogo descrito na distopia futurista de Ernest Cline. Antes mesmo da publicação do livro, WARNER BRos sai na frente de outros estúdios e compra os direitos de adaptação, respeitando as duas condições estipuladas por Cline: escrever a primeira versão do roteiro e a direção de Steven Spielberg, cujos filmes são inclusive mencionados na trama e parte das referências das pistas para encontrar o tal 'ovo de Páscoa'14 escondido entre os milhares de mundos virtuais do jogo. Cline consegue fazer parte da escritura do roteiro adaptado ${ }^{15}$, e o resultado dessa colaboração é analisada com esmero por Araújo e Marins.

As autoras fazem uma lúcida análise da narrativa-game, o videogame ficcional da história, utilizando proeminentes autores de mídias digitais, e observam a interpretação das referências geeks propostas no jogo, além do enredo deste na vida do criador do jogo. O ensaio destaca as referências culturais surgidas no último nível do jogo, The Crystal Key, observando que a narrativa cinematográfica expande 0 arco narrativo de Halliday, aproximando-o da mídia cinemática e videogame. As autoras dissecam com maestria a tradução de referências culturais em imagens com recursos

\footnotetext{
${ }^{14}$ Em Ready Player One (2011), a humanidade vive praticamente dentro de uma realidade virtual, evitando ambientes abertos e contato presencial, por coincidência ressoando com a pandemia de Covid 19. James Hallyday, criador dessa Plataforma virtual MMORPG [Massively Multiplayer Online Role-Playing Game], deixa seu patrimônio e o controle de sua empresa ao jogador que descobrir as pistas com temas relacionados aos anos 1980 e chegar ao centro da charada ao encontrar o Easter Egg.

${ }^{15}$ Os créditos apontam o experiente roteirista Zak Penn e Ernest Cline. Isso quer dizer que o primeiro trabalhou sobre o texto do segundo, tornando-o mais 'filmável', adicionando ou retirando cenas; ao contrário do sinal \&, o qual sinaliza uma criação conjunta. Conferir todos os créditos no IMDB: Disponível em https://www.imdb.com/title/tt1677720/?ref_=ttfc_fc_tt. Acesso 29 jan. 2021.
}

TradTerm, São Paulo, v.38, fevereiro/2021, p. 1-19

Número Especial - III JOTA

www.revistas.usp.br/tradterm 
audiovisuais, indicando como o filme transcodifica as descrições e narrações lidas no romance.

Voltamos à Espanha, mais precisamente Catalunha, com o trabalho de Roseli Barros da Cunha, que examina a original adaptação escrita e dirigida pelo basco Pablo Berger do conhecido conto infantil, Branca de Neve (1812) recolhido da cultura oral pelos irmãos Grimm. Blancanieves (2012) é um longa-metragem em branco e preto e mudo, com intertítulos em espanhol que transporta o conto popular para Andaluzia do início do século passado (1910), utilizando elementos ciganos e da cultura ibérica, como touradas e baile flamenco. O filme faz referências à Carmen (1845) de Prosper Mérimée, assim como à ópera com mesmo título, Georges Bizet (1875), e Carmen la de Triana (1938), filme de Florián Rey.

Cunha observa as relações intermidiáticas entre fonte e adaptação partindo de duas traduções para o português: Tatiana Belinky (2013) e Christine Röhrig (2014), focando na transposição da cultura andaluza. Para isso, utiliza estudos em intermidialidade e analisa a caracterização de Branca de Neve e seus pais, como também o lugar e época. Logo no início do filme, localizamos a história em Sevilla, num contexto cultural flamenco cigano e tauromaquia.

A protagonista não é filha de reis, entretanto seu pai possui prestígio e destaque em seu círculo social por conhecido toureiro, e sua mãe, uma formosa bailadora de flamenco. A autora ressalta o sincretismo entre a superstição cigana e a religiosidade e devoção proveniente da Santa Igreja Católica. Coincidentemente, surge neste artigo outra menção ao praxinoscópio, desta vez girando com figuras de um toureiro, aludindo à passagem do tempo. Outra diferença em relação ao conto é o reencontro entre a filha e seu pai, que logo morre.

A órfã perde a memória após ser quase morta por sua madrasta, é salva por uma trupe de anões circenses, e torna-se um sucesso ao integrar as 'touradas' teatralizadas. Ao ser rebatizada, um dos seus novos amigos explicita a conexão da adaptação com sua fonte: "Te llamaremos Blancanieves, como la del cuento". Assim como no conto popular, a

TradTerm, São Paulo, v.38, fevereiro/2021, p. 1-19

Número Especial - III JOTA

www.revistas.usp.br/tradterm 
protagonista de Berger acorda e volta à vida após ser beijada. Entretanto, não existe um salvador e um subentendido final feliz principesco, mas espectadores do espetáculo de circo tentando despertá-la com um beijo, repetidamente. No filme, mesmo empoderada e dominando as artes do flamenco e touradas, ela segue o destino trágico das outras Carmens.

Laura Cristina de Souza Zanetti e Vera Helena Gomes Wielewicki guiam - leitor pela fantasia e mitologia vikings, e trazem com elegância a contemporânea reflexão sobre estereótipos na representação da mulher em obras artísticas. Abordam elementos tidos como 'feministas' da cultura nórdica na obra inglesa $O$ Senhor dos Anéis (1954-1955) ${ }^{16}$, reforçados na adaptação para o cinema. As pesquisadoras examinam a adaptação da personagem feminina Éowyn em As Duas Torres e O Retorno do Rei, dois dos filmes da trilogia produzida, dirigida e parcialmente escrita pelo neozelandês Peter Jackson no início deste milênio (2001-2003).

Após mapear a presença da personagem escolhida para a análise, a nobre Éowyn, anotam semelhanças com explorações de cunho histórico sobre mulheres nórdicas, comparando sempre com a representação da princesaguerreira na obra de Jackson. Não se esquecem de Aragorn, distinto da fonte literária, muito mais suave e compreensivo no filme. Zanetti e Wielewicki acreditam que o protagonista masculino é apropriado para o cinema, transforma-se alguém a ser admirado, conquista o público, garantindo assim, chances de sucesso e comercialização.

Voltando ao tema da conferência inaugural da última JOTA (Carmell, 2019), Marketing e adaptação, recordamos a importância de agradar a vários setores do público com um mesmo filme, especialmente no caso de blockbuster familiar. A lucrativa e bem recebida trilogia, brinda fantasia e mágica, recheada de ação e aventura para os jovens e adultos, e alguns acenos específicos, como uma aparente lealdade ao texto literário, reproduzindo bem de perto algumas passagens queridas aos muitos fãs do livro. Outro gesto, desta vez uma característica comum aos filmes comerciais

\footnotetext{
${ }^{16}$ Traduzida em mais de setenta países, a primeira tradução integral em português da obra de J. R. R. Tolkien (publicada na década de 1990) foi assinada por uma das autoras deste número, Lenita Maria Rimoli Esteves, junto com Almiro Pisetta, tradutor dos poemas.
}

TradTerm, São Paulo, v.38, fevereiro/2021, p. 1-19

Número Especial - III JOTA

www.revistas.usp.br/tradterm 
é justamente a suavização de Aragon, lapidado para despertar interesse do público feminino. Adaptado e apropriado mais uma de uma vez para TV, musicais e videogames, a saga épica de Tolkien recebeu mais releituras após o sucesso da trilogia de Jackson ${ }^{17}$, especialmente na forma de jogos eletrônicos. Atualmente, AMAZON STUDIOS produz uma série com várias temporadas ambientada em uma era anterior aos eventos dos filmes, portanto em forma de prequel, ampliando o corpus de adaptações para pesquisas futuras.

Apresentamos outro trabalho sobre uma adaptação carregada de tintes autorais, "A Queda da Casa de Usher, espacialidade gótica e a adaptação cinematográfica de Jess Franco". Adriane Augusta Viana aborda a interpretação livre do conto de Poe, Neurosis - The Fall of the House of Usher $(1987)^{18}$ assinada pelo diretor espanhol Jess Franco. One-man-show, o madrilenho escreve, produz, dirige, fotografa e atua em muitos dos seus cerca de 200 filmes, de distintos gêneros (inclusive sexploitation), realizando igualmente a pós-produção, editando e compondo a trilha musical, todavia pouco estudado no Brasil.

Reconhecendo a grande quantidade e diversidade de adaptações do conto, Viana estuda a visceral versão autoral de Franco, centrando a análise do seu artigo na casa mal-assombrada e seu poder sobre os ocupantes, um dos aspectos mais mantidos nas adaptações da narrativa. Ela foca com destreza, como a adaptação de Franco lida com intertextualidade, elementos góticos, a fortuna crítica de Poe e do conto, além das outras versões criadas pelo mesmo Franco, com cenas inseridas na obra estudada. 0 cineasta editava seus filmes com elementos reaproveitados, por exemplo, o protagonista, Orloff, personagem de um romance inédito seu e de outras obras, como o filme $O$ Estripador (1976) ou O Terrível Dr. Orloff (1962).

Viana encontra mais diferenças que semelhanças com a matriz de Poe, visualizando um afastamento em relação à mesma, podendo ser chamada de

17 O filme, considerado um dos mais rentáveis da indústria, gerou receita de quase três bilhões de dólares, recebendo 17 Oscars, entre outros prêmios. Conferir mais informações no IMDB. Disponível em: https://www.imdb.com/title/tt0120737/?ref_=nv_sr_srsg_0. Acesso em 29 jan. 2021.

${ }^{18} \mathrm{O}$ filme é a terceira adaptação de Franco para esse mesmo conto, único comercializado em vídeo. El Hundimiento de la Casa Usher (1983), e Los Crímenes de Usher (1984) são dois filmes com enredos diferentes, afirma Viana.

TradTerm, São Paulo, v.38, fevereiro/2021, p. 1-19

Número Especial - III JOTA

www.revistas.usp.br/tradterm 
uma domesticação. No filme, a personagem (o narrador em Poe) recebe um nome, não mais assumindo o papel de narrador da história e o ambiente externo não sugere a melancolia e escuridão do conto, substituído por um espaço luminoso, solar, que segundo a pesquisadora é "um dos vários recursos estilísticos próprios de Jess Franco". O Usher desse diretor é um assassino em série e consciente de seus macabros experimentos, distinto daquele de Poe, que enterra por engano a irmã cataléptica. Outra mudança feita no filme é a ausência do lago, com papel trágico no desfecho do conto. 0 cenário fúnebre é transposto para a parte interna da casa, com ajuda de sombras e técnicas de iluminação, remetendo, conforme descreve a autora, às referências ligadas a Drácula de Stoker, e aqui adicionamos filmes anteriores, os quais seguramente inspiraram Franco.

Seguindo o mesmo tom gótico, Laura de Almeida e seu aluno Arthur Yerro Oliveira Santos compartilham um estudo comparativo entre Frankenstein or, The Modern Prometheus (1818) de Mary Shelley e duas de suas inúmeras adaptações ${ }^{19}$ : Frankenstein (1931) dirigido por James Whale e Victor Frankenstein (2015) de Paul McGuigan. O artigo destaca a personagem de Victor, mantida nas duas obras com diferenças, o primeiro filme mostra um 'cientista louco', condizente com o gênero Terror. Na adaptação deste milênio, Victor é "excêntrico e singular".

Conforme ainda crítica jornalística recolhida por Jason Colavito (2008: 97), a primeira adaptação, encenada em $1823^{20}$, é elogiada pela criação do assistente de Dr. Victor Frankenstein, Fritz, hoje conhecido por Igor. Essa personagem, inexistente no texto de Shelley, conserva-se até hoje nas adaptações. Estreia no cinema como Fritz no filme homônimo dirigido por Whale em 1931, mesmo nome utilizado em Victor Frankenstein de McGuigan, ambos estudados no artigo.

19 Como muitos clássicos, o livro é adaptado desde sua escritura em prosa, quadrinhos e graphic novels, peças teatrais e musicais, e videogames, além de ter sido adaptado em mais de uma centena de filmes e até como enredo de escola de samba. A história foi adaptada em seu centenário pela Beija Flor com o título Monstro é aquele que não sabe amar. Os filhos abandonados da pátria que os pariu (2018) recebendo o primeiro lugar dos desfiles (COBELO 2019).

20 A peça Presumption; or, the Fate of Frankenstein (1823) de Richard Brinsley Peake, apresentada na English Opera House em Londres, é a única adaptação assistida pela própria Shelley.

TradTerm, São Paulo, v.38, fevereiro/2021, p. 1-19

Número Especial - III JOTA

www.revistas.usp.br/tradterm 
O número especial apresenta ainda análises sobre produções nacionais. João Victor de Souza-Ramos, Ewerton de Freitas Ignácio e Maria Eugênia Curado trabalham com dois autores goianos: o escritor Bernardo Élis, imortal da ABL e a diretora de cinema Rosa Berardo. A obra explorada, André Louco, é um conto com traços regionalistas escrito por Élis, parte do seu primeiro livro de narrativas curtas, Ermos e Gerais (1944). Os autores creem que a "construção narrativa apresenta digressões com cortes de cenas que se assemelham a takes cinematográficos", justificando uma leitura cinemática. Sua conterrânea Rosa Berardo, com formação acadêmica em cinema, pósdoutorado e cursos de extensão no exterior, faz sua estreia com uma adaptação em forma de curta-metragem (16:30 min.) em branco e preto, repetindo o título da obra matriz.

Os autores observam como o curta, uma tradução intersemiótica bem próxima ao livro, reproduzindo até falas, além de cenas, de forma literal, dialoga com o conto, iluminados por um dos poucos críticos do país da área: Júlio Plaza. Ocorre uma divergência, porém, no foco narrativo, com a retirada do narrador-personagem, mas Berardo explora bem essas "novas configurações a partir das especificidades semióticas de sua mídia", como bem descrevem Souza-Ramos et ali nesse estimulante artigo.

Encerramos apresentando um artigo assinado por dois membrosfundadores do GREAT e da comissão organizadora da III Jota 2019: Paulo Edson Alves Filho e Juliana Hass. Eles se debruçam sobre uma produção nacional, desta vez uma incomum adaptação teatral de um texto literário e suas duas versões fílmicas.

O premiado romance Il Buio e il Miele (1969) ${ }^{21}$ de Giovanni Arpino é adaptado pelo filme italiano dirigido por Dino Risi Profumo di Donna (1974), escrito em colaboração com o experiente roteirista Ruggero Maccari, que inclusive divide a nominação de Oscar para melhor roteiro adaptado, sendo Vitorio Gassman premiado como melhor ator em Cannes. As duas obras são empregadas como referência para o filme dirigido e produzido por Martin Brest, Scent of a Woman (1992), e escrito por Bo Goldman, um dos mais

\footnotetext{
${ }^{21}$ Foi traduzido aqui por Lavínia Aguilar, com o título $A$ Escuridão e o Mel (2001).

TradTerm, São Paulo, v.38, fevereiro/2021, p. 1-19

Número Especial - III JOTA

www.revistas.usp.br/tradterm
} 
respeitados e premiados roteiristas da indústria do cinema ${ }^{22}$, o qual recebeu um Oscar por esse roteiro, acompanhado pelo Oscar de protagonista premiando Al Pacino, mesmo substancialmente distinto do primeiro, especialmente quanto a sua forma de ser, seu acompanhante e sua relação com a figura feminina.

A única adaptação teatral dessa obra segue o livro italiano de perto, conservando a ambientação e tempo histórico, mas imprime sua marca na produção desde o início. Após adquirir os direitos da obra, Silvio Guindane ${ }^{23}$ convida Pedro Brício e Walter Lima Jr. para adaptar o texto, e além de produzir o espetáculo, ainda assume o papel principal.

Com um elenco diverso, protagonista negro e uma drag queen, a peça expande significativa da figura feminina, quase ausente no filme americano, e que abre o espetáculo nesta adaptação. Os dois pesquisadores também utilizam Plaza, e atentam justamente para esse diálogo entre esses distintos meios, notando as especificidades e a utilização delas por cada adaptação. A direção de um cineasta, Walter Lima Jr. carrega a peça de tons fílmicos, como a solução para cenas externas através de signos cinemáticos utilizando um videowall com projeções e iluminação com efeitos sonoros, recriando algumas cenas hoje clássicas do filme de Martin Brest, como o passeio numa Ferrari vermelha e a mais famosa e reconhecível do longa, a cena em que o casal dança um tango argentino.

Esta edição da Tradterm/JOTA materializa o interesse pelos Estudos da Tradução no Brasil e especialmente o evidente crescimento dos Estudos da Adaptação, incluindo os Estudos Intersemióticos.

\footnotetext{
${ }^{22}$ Segundo IMDB, o novaiorquino é um dos poucos roteiristas que recebem o tipo de reverência geralmente reservada a diretores, e um dos mais galardoados, com vários prêmios de melhor roteiro original e adaptado tanto para o cinema, como para seriados de TV. Recebeu Oscar pela adaptação One Flew Over the Cuckoo's Nest (1976), entre outros filmes não creditados, como Ragtime (1981) e Dick Tracy (1990), entre outros. Conferir mais detalhes sobre sua biografia no IMDB, disponível em: https://www.imdb.com/name/nm0325743/bio?ref_=nm_ov_bio_sm . Acesso 30 jan. 2021.

${ }^{23} \mathrm{O}$ espetáculo Perfume de Mulher viajou pelo Brasil e exterior, primeiro com Natália Lage e depois Gabriela Duarte no papel feminino, apresentado em 2019 e 2020, sendo interrompido pela pandemia. Correio do Povo, disponível em: https://www.youtube.com/watch?v=GRDBQh9NyvY e Mala Cultural, citado no artigo comentado.

TradTerm, São Paulo, v.38, fevereiro/2021, p. 1-19

Número Especial - III JOTA

www.revistas.usp.br/tradterm
} 
Esta é uma oportunidade única para conhecer novas metodologias, críticos, autores e obras dentro desta área. Oferecemos 16 pesquisadores dialogando sobre tradução e adaptação em suas recentes pesquisas. Nesta torre de Babel, querido leitor, além de incontáveis línguas, descobrimos múltiplos meios de recontar histórias. Vale.

Gostaríamos de agradecer a Luiza Lotufo, monitora do Citrat, pelo auxílio inestimável na edição deste número da revista.

\section{Referências}

BAZIN, A. What Is Cinema?. Volumes 1 and 2. Berkeley: University of California Press, 2005

CARDWELL, S. Adaptation revisited: Television and the classic novel. Manchester: Manchester University Press, 2002.

CarTmell, D. A Companion to Literature, Film, and Adaptation. Hoboken: John Wiley \& Sons, 2012.

CARTMELL, D.; SCOTT, M. (eds.). Talking Shakespeare: Shakespeare into the millennium. New York: Macmillan International Higher Education, 2017.

Colavito, J. (ed.) "A Hideous Bit of Morbidity": An Anthology of Horror Criticism from the Enlightenment to World War I. Jefferson: McFarland, 2008.

Cobelo, S. "Don Quijote y el Carnaval de Brasil - Una historiografía carnavalesca". Actas del XX Congreso de la Asociación Internacional de Hispanistas (AIH), Jerusalém, Israel, 2019 (no prelo).

D’ARCAnGel, L. "Lo stupro by Franca Rame: Political Violence and Political Theatre". In: Antonello, P.; O'LeARY, A. (eds.) Imagining terrorism: the rhetoric and representation of political violence in Italy 19692009. v. 18. London: MHRA, 2009, p. 101-115.

ELLIOT, K. Rethinking the Novel/Film Debate. Cambridge: Cambridge University Press, 2003.

LATHEY, G. (ed.). The translation of children's literature: A reader. Bristol: Multilingual matters, 2006.

TradTerm, São Paulo, v.38, fevereiro/2021, p. 1-19

Número Especial - III JOTA

www.revistas.usp.br/tradterm 
Mello, A. B. Bela, depravada e do lar: como traduzir(am) 'Tutta casa, letto e chiesa', de Franca Rame e Dario Fo, no Brasil. Dissertação de Mestrado em Estudos Literários da Faculdade de Letras da Universidade Federal de Minas Gerais (UFMG), 2019.

Milton, J. "Adaptation". In: Gambier, Y.; Van DoorsLaer, L; (eds.). Handbook of Translation studies. Vol. 1. Amsterdam: John Benjamins Publishing, 2010:3-6.

Milton, J.; ToRres, M.-H. C. "Apresentação”. Cadernos de Tradução, v. 11, n. 1, 2003, p. 9-17.

HUtCheON, L.; O'FlynN, S. A Theory of Adaptation. Abingdon: Routledge, 2013.

SANDERS, J. Adaptation and Appropriation. Abingdon: Routledge, 2015.

SousA, C. A. Atos de tradução para o monólogo-Contrasto per una sola voce-de Dario Fo e Franca Rame. Dissertação de Mestrado em Literatura e Cultura da Universidade Federal da Bahia (PPGLitCult-UFBA), 2009.

StaM, R. Film Theory: An Introduction. Oxford: Blackwell, 2000.

Stam, R.; Raengo, A. A Companion to Literature and Film. Hoboken: John Wiley \& Sons, 2008.

ZATLIN, P. Theatrical Translation and Film Adaptation: a practitioner's view. Bristol: Multilingual Matters, 2005. 